\title{
Drug loaded biodegradable polymer microneedles fabricated by hot embossing
}

Andersen, Thor Emil; Andersen, Alina Joukainen; Petersen, Ritika Singh; Nielsen, Line Hagner; Keller, Stephan Sylvest

Published in:

Microelectronic Engineering

Link to article, DOI:

10.1016/j.mee.2018.03.024

Publication date:

2018

Document Version

Peer reviewed version

Link back to DTU Orbit

Citation (APA):

Andersen, T. E., Andersen, A. J., Petersen, R. S., Nielsen, L. H., \& Keller, S. S. (2018). Drug loaded biodegradable polymer microneedles fabricated by hot embossing. Microelectronic Engineering, 195, 57-61. https://doi.org/10.1016/j.mee.2018.03.024

\section{General rights}

Copyright and moral rights for the publications made accessible in the public portal are retained by the authors and/or other copyright owners and it is a condition of accessing publications that users recognise and abide by the legal requirements associated with these rights.

- Users may download and print one copy of any publication from the public portal for the purpose of private study or research.

- You may not further distribute the material or use it for any profit-making activity or commercial gain

- You may freely distribute the URL identifying the publication in the public portal

If you believe that this document breaches copyright please contact us providing details, and we will remove access to the work immediately and investigate your claim 


\title{
Drug Loaded Biodegradable Polymer Microneedles Fabricated by Hot Embossing
}

\author{
Thor Emil Andersen, Alina Joukainen Andersen, Ritika Singh Petersen, \\ Line Hagner Nielsen, Stephan Sylvest Keller
}

The Danish National Research Foundation and Villum Foundation's Center for Intelligent Drug Delivery and Sensing Using Microcontainers and Nanomechanics (IDUN), Department of Micro- and Nanotechnology, Technical University of Denmark, Ørsteds Plads 345C, 2800, Kgs. Lyngby, Denmark

Key Words: Microneedles, transdermal, drug delivery, hot embossing, poly- $\varepsilon$-caprolactone (PCL)

\begin{abstract}
This study demonstrates a fast low temperature method for fabrication of drug loaded polymer microneedles (MNs). First, arrays of tapered pillar MNs with a length of $275 \pm 3 \mu \mathrm{m}$ (mean \pm SD) and a diameter of $84 \pm 1 \mu \mathrm{m}$ were fabricated in Si with a three-step deep reactive ion etching (DRIE) process. The Si MNs were used as a template for fabrication of polydimethylsiloxane (PDMS) stamps. The stamps were applied for replication of the MNs in spin coated poly- $\varepsilon$-caprolactone (PCL) films by hot embossing at $60^{\circ} \mathrm{C}$ and a pressure of $1.4 \mathrm{MPa}$ for $3 \mathrm{~min}$. The resulting PCL MNs perfectly resembled the $\mathrm{Si}$ MNs and had a length of $270 \pm 5 \mu \mathrm{m}$ and a diameter of $84 \pm 3 \mu \mathrm{m}$. The MNs had sufficient mechanical strength to penetrate the surface of a $10 \mathrm{w} / \mathrm{w} \%$ gelatine gel without deformation. Finally, PCL MNs containing $20 \mathrm{w} / \mathrm{w} \%$ of furosemide were fabricated and drug release by diffusion was demonstrated.
\end{abstract}

\section{Introduction}

In the late 90's, microneedles (MNs) were introduced as a novel method for (trans)dermal drug delivery [1]. A large number of different types of MNs were reported, such as dissolvable polymer MNs [2], hollow silicon MNs for drug injection [3] or coated biodegradable MNs for vaccine delivery [4]. MNs are less invasive and less painful compared to traditional hypodermic needles [5]. Arrays containing hundreds of MNs can be fabricated on a footprint area of a few $\mathrm{mm}^{2}$. Drug loaded polymer MNs are in most cases fabricated by solution casting methods [6-9]. In this case, small amounts of drug-polymer solutions are cast on moulds typically made of silicones such PDMS. Alternatively, spray coating was used to deposit drug polymer solutions into PDMS MN moulds [10]. Furthermore, drawing lithography techniques or electro drawing from droplets at ambient temperature were introduced for fabrication of dissolvable MNs $[11,12]$. Most of these methods have the drawback that they are time consuming and not suitable for large-scale production.

In comparison, hot embossing is a versatile micro moulding process for the fast replication of polymer microstructures with high aspect ratio [13]. Typically, hot embossing only requires a short polymer flow allowing lower moulding temperatures compared to other micro moulding techniques [14]. Hot embossing of MNs has been demonstrated using polylactic acid (PLA) [15], poly(methyl methacrylate) (PMMA) [16, 17], polycarbonate (PC) [18-20] and cyclic olefin copolymer (COC) [19]. However, none of these MNs were loaded with drug. A major drawback in all of these studies is a long cycle time at high processing temperatures above $150^{\circ} \mathrm{C}$. Those conditions will affect a considerable range of drugs and prevent that active pharmaceutical ingredients can be pre-loaded in the polymer film.

$\mathrm{PCL}$ is a biodegradable polymer with a low melting temperature of $59-64^{\circ} \mathrm{C}$ [21]. This facilitates micro moulding processes and identifies $\mathrm{PCL}$ as a potential matrix for drugs that are unable to withstand high temperatures, such as proteins and peptides. Additional advantages of $\mathrm{PCL}$ are high permeability for many drugs and good biocompatibility [21]. Here, we demonstrate the direct fabrication of drug loaded $\mathrm{MNs}$ in a single step of hot embossing at low 
temperature, low pressure and with short cycle time (Figure 1). For this purpose, Si MNs were fabricated with a multi-step DRIE process and replicated in PDMS. The resulting PDMS stamp was applied for hot embossing of MNs in spin-coated PCL films loaded with the drug furosemide. Furosemide was selected as model drug because it is a small molecule drug that is poorly soluble in intestinal media (class IV in Biopharmaceutics Classification System (BCS)) resulting in challenges for delivery via the oral route. Finally, the mechanical stability of the MNs and drug release were investigated.

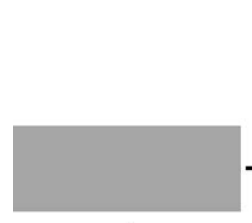

a)

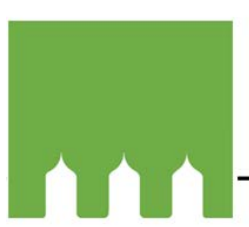

d)

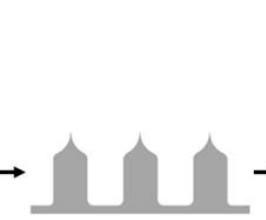

b)

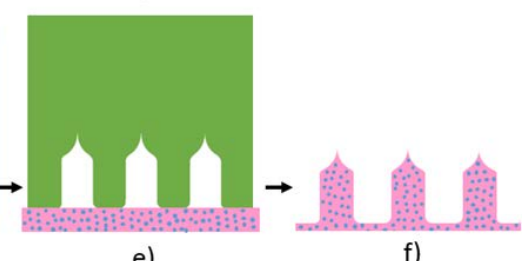

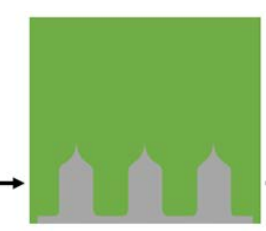

c)
Figure 1 - Schematic representation of the overall fabrication process. a) Si wafer; b) Si MNs fabricated by multi-step DRIE; c) PDMS casting d) Demoulding of PDMS stamp; e) Hot embossing in PCL film containing furosemide. f) Final furosemide-loaded polymer MNs.

\section{Material and Methods}

\subsection{Fabrication of Si MNs and PDMS Stamps}

A multi-step DRIE process in a Pegasus ASE (STS Technologies Ltd., Great BritainUnited Kingdom), similar to a method described by Griss et al. [22], was optimized to fabricate tapered pillar Si MNs. 1 $\mu \mathrm{m}$ thick $\mathrm{SiO}_{2}$ was patterned by standard UV photolithography with $1.5 \mu \mathrm{m} \mathrm{AZ}{ }^{\circledR}$ MiR 701 (Microchemicals $\mathrm{GmbH}$, Germany) serving as the etch mask. First an isotropic etch step was performed to define the tip of the MNs. The isotropic etch was performed for $19 \mathrm{~min}$ at $20^{\circ} \mathrm{C}$, a pressure of $25 \mathrm{mTorr}$ and a $\mathrm{SF}_{6}$ flow of $150 \mathrm{sccm}$. The coil power was set to $600 \mathrm{~W}$ and the platen power to $3 \mathrm{~W}$. Subsequently, a Bosch process etched the shafts of the MNs for $37 \mathrm{~min} 20 \mathrm{sec}$.
The deposition step of the Bosch process was performed at $0^{\circ} \mathrm{C}$ for $1 \mathrm{sec}$. The pressure was $20 \mathrm{mTorr}$ and the flow of $\mathrm{C}_{4} \mathrm{~F}_{8}$ was $150 \mathrm{sccm}$. The coil power was $2000 \mathrm{~W}$ and the Platen power $0 \mathrm{~W}$. The etch step of the Bosch process was $2.2 \mathrm{sec}$ long and the pressure was 26 mTorr. The $\mathrm{SF}_{6}$ flow was $275 \mathrm{sccm}$ while the $\mathrm{O}_{2}$ flow was $5 \mathrm{sccm}$. The coil power was set to $2500 \mathrm{~W}$ and the Platen power was set to $35 \mathrm{~W}$. The third etch step consisted of an isotropic etch, which sharpened the tips of the MNs and resulted in complete under-etch of the etch masks. This etch step was 5 min $30 \mathrm{sec}$ long and performed with the same parameters as the first etch step. A mould for fabrication of a negative PDMS stamp was prepared by placing a Si MN array with size of $8.5 \times 8.5 \mathrm{~mm}$ in a PMMA frame. Sylgard ${ }^{\circledR} 184$ silicone (Dow Corning Corporation, USA) was mixed in 10:1 weight-toweight ratio of elastomer and curing agent and thereafter poured into the mould. After curing for $12 \mathrm{~h}$ at $60^{\circ} \mathrm{C}$ the negative PDMS stamps were demoulded from the MN arrays. The MN arrays remained intact after demoulding and could be reused.

\subsection{Preparation of Furosemide-loaded PCL Films}

For the first evaluation of the hot embossing process and mechanical stability of PCL MNs, pure PCL films were fabricated similarly to Nagstrup et al. [13]. A $15 \mathrm{w} / \mathrm{w} \% \mathrm{PCL}$ solution was prepared by mixing PCL granulate $(80 \mathrm{~kg} / \mathrm{mol})$ (Sigma-Aldrich, USA) with dichloromethane (Sigma-Aldrich, USA). The solution was heated to $50^{\circ} \mathrm{C}$ and stirred for $12 \mathrm{~h}$ resulting in a clear and homogenous solution. The $\mathrm{PCL}$ films were fabricated by spin coating a 4 inch Si wafer with three layers of PCL solution. Each layer was coated at a spin speed of $800 \mathrm{rpm}$ for $1 \mathrm{~min}$ and subsequently dried for $5 \mathrm{~min}$ before applying the next layer. The films were peeled off the wafer and cut into pieces of approximately $15 \times 15 \mathrm{~mm}$. Thickness measurements were performed with an Alpha-Step IQ Stylus profiler (KLA-Tencor, USA). The film thickness was measured to be $194 \pm 13 \mu \mathrm{m}$ (mean \pm SD). For direct embossing of drug loaded MNs, PCL films loaded with $20 \mathrm{w} / \mathrm{w} \%$ furosemide were prepared [23]. A PCL-furosemide (PCL-F) solution was pre- 
pared by mixing $8 \mathrm{~g}$ of PCL granulate with $2 \mathrm{~g}$ of furosemide (Fargon Nordic A/S, Denmark) in $20 \mathrm{~mL}$ of dichloromethane, and $40 \mathrm{~mL}$ of acetone (Sigma-Aldrich, USA). The solution was heated to $40^{\circ} \mathrm{C}$ and stirred at $300 \mathrm{rpm}$ for $24 \mathrm{~h}$ resulting in a clear and homogenous solution. The PCL-F films were fabricated by spin coating four layers of PCL-F solution. Each layer was coated at a spin speed of $400 \mathrm{rpm}$ for $1 \mathrm{~min}$ and subsequently dried for $5 \mathrm{~min}$ before applying the next layer. The resulting film thickness was measured to be $115 \pm 5 \mu \mathrm{m}$. The films were stored for drying at ambient temperature for several days to ensure complete evaporation of the highly volatile solvents before further processing.

\subsection{Fabrication of Polymer Microneedles}

A bonding press with a force gauge and heat controller (Paul-Otto Weber GmbH, Germany) was used for the hot embossing process. The PDMS stamp and a piece of PCL/PCL-F film were placed in the bonding press, which was heated to $60^{\circ} \mathrm{C}$. A pressure of $1.4 \mathrm{MPa}$ was applied for $3 \mathrm{~min}$ in order to achieve complete filling of the MN cavities of the stamp. The pressure was then released and the setup was cooled down to $24^{\circ} \mathrm{C}$. Finally, the polymer $\mathrm{MN}$ array was peeled off the stamp. SEM examination and measurement of $\mathrm{MN}$ dimensions were performed in a Zeiss Supra 40 VP (Carl Zeiss AG, Germany).

\subsection{Gelatine Penetration Test}

A $10 \mathrm{w} / \mathrm{w} \%$ gelatine gel (Gelatine from porcine skin, gel strength 300 , Type A, Sigma-Aldrich, USA) was prepared by heating to $53^{\circ} \mathrm{C}$ and stirring for $3 \mathrm{~h}$ at $100 \mathrm{rpm}$. The solution was poured into a mould with a diameter of $20 \mathrm{~mm}$ and a depth of $9 \mathrm{~mm}$. The gel was cooled to room temperature $\left(24^{\circ} \mathrm{C}\right)$ before it was placed in a fixture preventing sideways movement of the gelatine during the test. A MN sample with diameter of $6 \mathrm{~mm}$ and an average array consisting of $275 \pm 6 \mathrm{MNs}$ was punched out of the PCL MN array using a biopsy punch and placed on the gelatine sample. A TA.XT Texture Analyzer (Stable Micro

Systems, Great Britain) with a $10 \mathrm{~kg}$ load cell and a $10 \mathrm{~mm}$ probe was used to push the MN sample into the gelatine gel and simultaneously measure the exerted force. The test was initiated when reaching a force of $0.03 \mathrm{~N}$. The probe pushed the $\mathrm{MN}$ sample at $0.01 \mathrm{~mm} / \mathrm{s}$ until an indentation depth of $2.5 \mathrm{~mm}$ was reached. After the penetration test, the $\mathrm{MN}$ samples were examined in the SEM and the gelatine was examined under a Zeiss LSM700 confocal microscope (Carl Zeiss AG, Germany) to identify failure of the $\mathrm{MNs}$ and penetration of the gelatine gel, respectively.

\subsection{In vitro drug release}

The in vitro release of furosemide from MNs was measured in real time using UV absorbance in a similar setup as described earlier [24]. Before the release experiments, standard curves of furosemide were recorded in phosphate buffer (PBS) at pH 6.5. For the release experiments, $\mathrm{MN}$ samples were attached to cylindrical magnetic stirrers and placed in individual vials of a $\mu$ Diss Profiler (Pion inc, USA) with $10 \mathrm{~mL}$ of PBS. The release experiments were run at $37^{\circ} \mathrm{C}$ with a stirring rate of $100 \mathrm{rpm}$ and the mirrors mounted on the probes provided an optical path length of $1 \mathrm{~mm}$. Recorded spectra were analyzed in the wavelength range $310-350 \mathrm{~nm}$ over a period of $18 \mathrm{~h}$. For comparison, flat PCL-F film samples were prepared in the bonding press without stamp using identical embossing parameters as described above. The weight of each sample was measured prior to the release study using a microbalance in order to estimate the amount of furosemide.

\section{Results and Discussion}

\subsection{Microneedle fabrication}

The result of the Si MN fabrication process are tapered pillar MNs (Figure 2.a-b) with a height of $275 \pm 3 \mu \mathrm{m}$ and a diameter of $84 \pm 1 \mu \mathrm{m}$. The Si MNs were successfully replicated in $P C L$ and furosemide loaded PCL using the PDMS stamp. The resulting MNs shown in Figure 2.c-e have a height of $270 \pm 5$ $\mu \mathrm{m}$ and a diameter of $84 \pm 3 \mu \mathrm{m}$. The tip radius of the PCL MNs was around $1 \mu \mathrm{m}$ (Figure 2.d). As seen from the measurements and Figure 2 the $\mathrm{Si} M N$ and polymer MNs showed excellent replication fidelity. 

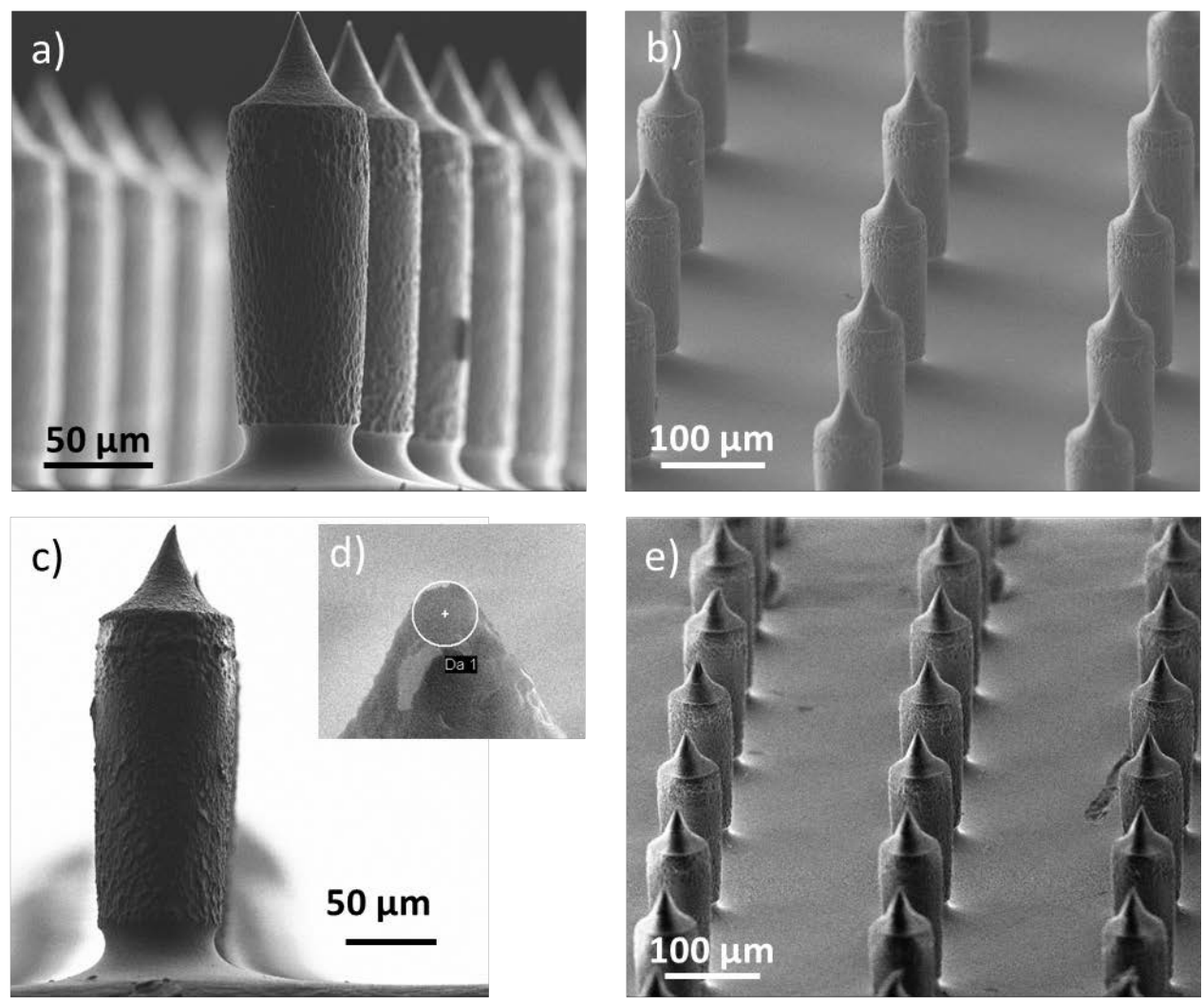

Figure 2 - SEM images of Si MNs (a-b) and PCL MNs (c-e) for comparison; tip radius in (e) is $1.05 \mu \mathrm{m}$ (white circle)

\subsection{Gelatine Penetration Test}

Examination of the gelatine gels and PCL MN samples after the penetration tests revealed that the MNs had created permanent indentations in the gelatine (Figure 3.a). The indentations in the centre of the imprint were less pronounced (Figure 3.b, depth $7 \mu \mathrm{m}$ ), while the indentations in the periphery of the imprint were comparatively larger (Figure 3. C, depth $17 \mu \mathrm{m})$. Furthermore, cracks were identified in some of the indentations, indicating that the MNs were able to penetrate the surface of the gelatine gel (Figure 3.d-e). However, penetration depth could not be evaluated quantitatively using confocal microscopy or by analysis of force displacement curves. This might be due to the bed-of-nails effect caused by too close proximity of neighbouring MNs resulting mainly in a deformation of the gelatine gel and not an actual penetration of the MNs at their full length [25]. The distance between the MNs should therefore be increased in future studies in order to improve gel penetration. The PCL MNs showed no signs of failure or deformation after the penetration test and all MNs were standing straight (Figure 3.f) even though the array was exposed to a compressive force of $0.7 \mathrm{~N}$ during the test.

\subsection{In vitro Drug Release}

Figure 4 shows the release curves with the concentration of furosemide in $10 \mathrm{~mL}$ PBS buffer at $\mathrm{pH}$ 6.5 measured by UV absorbance. Initially a faster release of drug is observed for the samples with MNs due to the larger surface area compared to the PCL$F$ films which was estimated to be $46.6 \mathrm{~mm}^{2}$ and $28.3 \mathrm{~mm}^{2}$, respectively. After 6 hours, the increase in concentration was similar for both types of samples. This might indicate that the MNs released all the furosemide and that further increase in concentration was due to drug release from the underlying film. The initial amount of furosemide loaded in the samples was estimated based on the mass before 

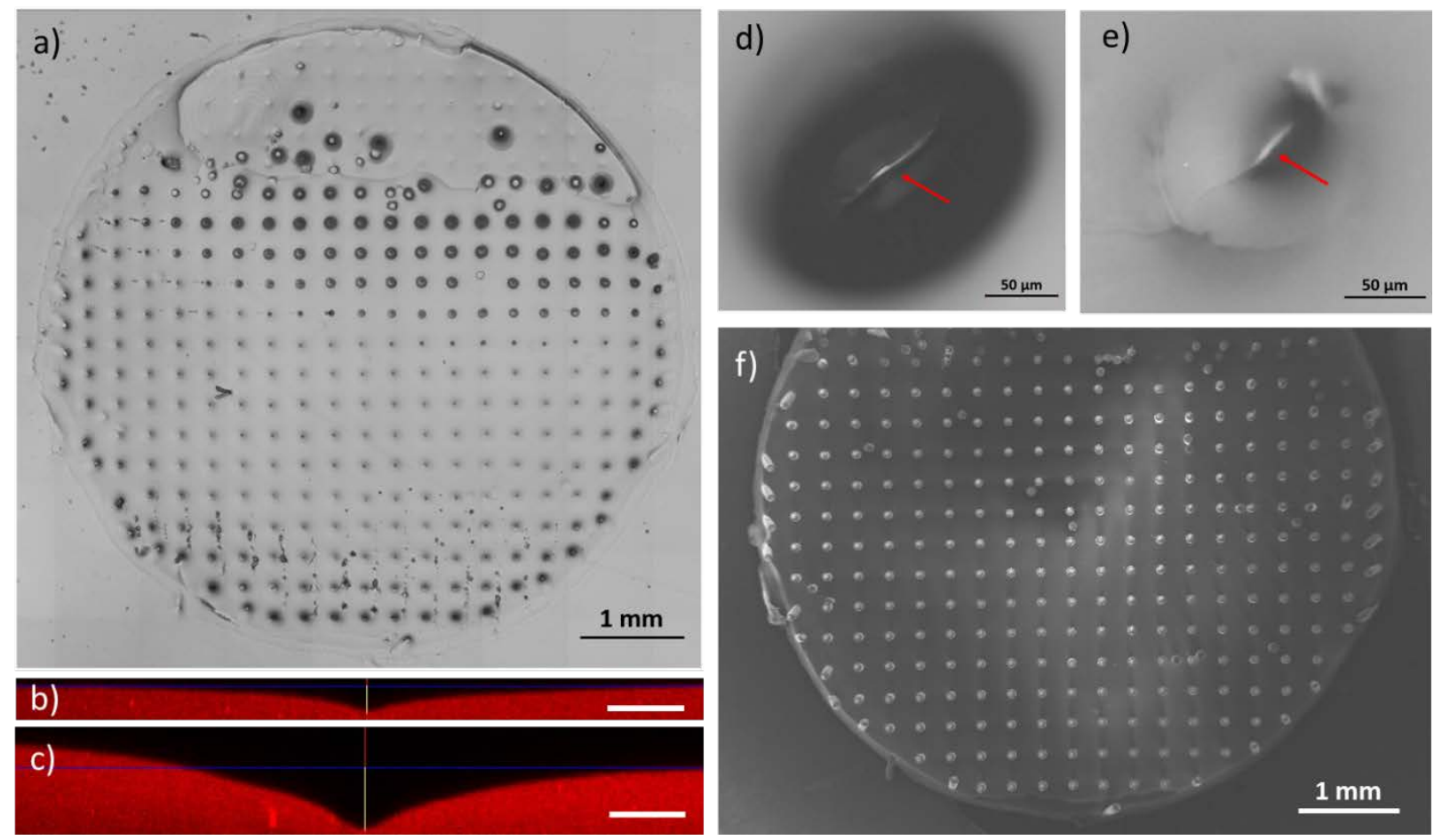

Figure 3 - a) imprint created by the $M N$ array shown in Figure 3(f); confocal microscopy profiles for indentations in the centre, depth $7 \mu$ m (b) and at the periphery, depth $17 \mu \mathrm{m}$ (c) of the gelatine; cracks observed for indentations at the periphery (d) and in the centre of the sample (e); f) top view of a MN array after the penetration test

the release experiments. Table 1 compares those values with the amount of furosemide released from the MNs and PCL-F films after 18 hours. More drug was released from the MNs compared to the films due to the larger initial volume of drug-polymer matrix. However, in both cases the released amount corresponded to close to $100 \%$ of the initial amount of drug loaded in the samples. The proportionality between the amount of released furosemide and initial amount of drug loaded in the samples indicates that the furosemide was homogenously distributed in the films and MNs.

Table 1 - Estimated drug load in MNs and film samples and amount of furosemide released after $18 \mathrm{~h}$ in PBS.

\begin{tabular}{lcccc}
\hline & $\begin{array}{l}\text { Total } \\
\text { Mass }\end{array}$ & $\begin{array}{c}\text { Estimated } \\
\text { amount of } \\
\text { Furosemide }\end{array}$ & $\begin{array}{c}\text { Released } \\
\text { amount of } \\
\text { Furosemide }\end{array}$ & $\begin{array}{c}\text { Released drug } \\
\text { compared to } \\
\text { initial amount }\end{array}$ \\
\hline MNs & $3.83 \mathrm{mg}$ & $0.77 \mathrm{mg}$ & $0.76 \mathrm{mg}$ & $99.4 \%$ \\
\hline Film & $3.33 \mathrm{mg}$ & $0.67 \mathrm{mg}$ & $0.65 \mathrm{mg}$ & $97.0 \%$ \\
\hline
\end{tabular}

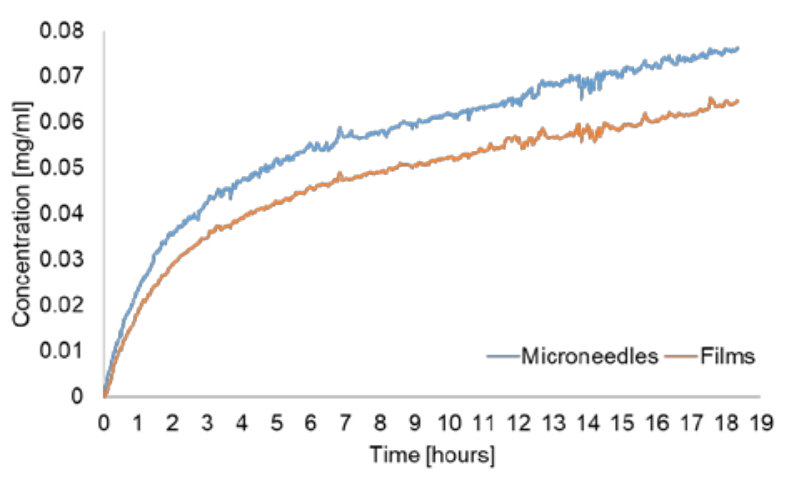

Figure 4-Release of furosemide drug in $10 \mathrm{~mL}$ PBS pH 6.5 from F-PCL films and arrays of $275 \mathrm{MNs}(\mathrm{N}=3)$.

\section{Conclusion}

In this study, tapered pillar MNs with a length of $275 \pm 3 \mu \mathrm{m}$ and a diameter of $84 \pm 1 \mu \mathrm{m}$ were fabricated in Si and subsequently, replicated in PCL with a fast, simple and low-temperature method. The MNs had the mechanical stability to withstand the forces of $0.7 \mathrm{~N}$ when in contact with $10 \mathrm{w} / \mathrm{w} \%$ gelatine gel and were able to create imprints and 
cracks indicating penetration of the gelatine gel. Furthermore, the hot embossing method allowed loading of the MNs with $20 \mathrm{w} / \mathrm{w} \%$ of the model drug furosemide and release by diffusion within $18 \mathrm{~h}$ at $37^{\circ} \mathrm{C}$. The shape and dimensions of the MNs are solely defined by the mask design and the etching times for the fabrication of the Si master and can be modified accordingly. In future studies, the influence of different $\mathrm{MN}$ geometries on the drug release will be studied.

\section{Acknowledgements}

The research is funded by the Danish National Research Foundation (DNRF122) and Villum Fonden (Grant No. 9301).

\section{References}

[1] K. Van Der Maaden, W. Jiskoot, J. Bouwstra, Microneedle technologies for (trans)dermal drug and vaccine delivery. J. Control. Release 161 (2012) 645655

[2] S.P. Sullivan, D.G. Koutsonanos, M. del Pillar Martin, J.W. Lee, V. Zarnitsyn, S.-O. Choi, N. Murthy, R.W. Compans, I. Skountzou, M.R. Prausnitz. Dissolving polymer microneedle patches for influenza vaccination. Nat. Med. 16 (2010) 915-20

[3] N. Roxhed, P. Griss, G. Stemme, Membranesealed hollow microneedles and related administration schemes for transdermal drug delivery. Biomed. Microdevices 10, 271-279 (2008).

[4] P.C. DeMuth, Y. Min, B. Huang, J.A. Kramer, A.D. Miller, D.H. Barouch, P.T. Hammond, D.J. Irvine. Polymer multilayer tattooing for enhanced DNA vaccination. Nat. Mater. 12, 367-76 (2013).

[5] H.S. Gill, D.D. Denson, B.A. Burris, M.R. Prausnitz, Effect of microneedle design on pain in human subjects. The Clinical Journal of Pain, 24(7) (2008) 585594.

[6] Q. L. Wang, D. D. Zhu, Y. Chen, and X. D. Guo, A fabrication method of microneedle molds with controlled microstructures, Mat. Sci. Eng. 65 (2016) 135-142
[7] M.-Ch. Chen, M.-H. Ling, K.-Y. Lai, E. Pramudityo, Chitosan microneedle patches for sustained transdermal delivery of macromolecules, Biomacromolecules 13 (2012) 4022-4031

[8] W.K. Raja, S. MacCorkle, I.M. Diwan, A. Abdurrob, J. Lu, F.G. Omenetto, D.L. Kaplan, Transdermal delivery devices: Fabrication, mechanics and drug release from silk, Small 9 (2013) 3704-3713

[9] R.F. Donnelly, R. Majithiya, T.R.R. Singh, D.I.J. Morrow, M.J. Garland, Y.K. Demir, K. Migalska, E. Ryan, D. Gillen, Ch.J. Scott, A.D. Woolfson, Design, optimization and characterisation of polymeric microneedle arrays prepared by a novel laser-based micromoulding technique, Pharm. Res. 28 (2011) 41-57

[10] M.G. McGrath, S. Vucen, A. Vrdoljak, A. Kelly, C. O'Mahony, A.M. Crean, A. Moore, Production of dissolvable microneedles using an atomised spray process: Effect of microneedle composition on skin penetration, Eur. J. Pharm. Biopharm. 86 (2014) 200-211

[11] K. Lee, H. Jung, Drawing lithography for microneedles: A review of fundamentals and biomedical applications, Biomaterials 33 (2012) 7309-7326

[12] R. Vecchione, S. Coppola, E. Esposito, C. Casale, V. Vespini, S. Grilli, P. Ferraro, P.A. Netti, Electrodrawn drug-loaded biodegradable polymer microneedles as a viable route to hypodermic injection, Adv. Funct. Mater. 24 (2014) 3515-3523

[13] J. Nagstrup, S. S. Keller, K. Almdal, A. Boisen, 3D microstructuring of biodegradable polymers, Microelec. Eng. 88 (2011) 2342-2344

[14] M. Heckele, W. K. Schomburg, Review on micro molding of thermoplastic polymers, J. Micromech Microeng. 14 (2004) 1-14

[15] H. C. Kuo, Y. Lin, Y. K. Shen, S. C. Kang, Invasive PLA microneedle fabrication applied to drug delivery system, Proc. MACE 2011 (2011) 5988769

[16] M. W. Zhu, H. W. Li, X. L. Chen, Y. F. Tang, M. H. Lu, Y. F. Chen, Silica needle template fabrication of 
metal hollow microneedle arrays, J. Micromech. Microeng. 19 (2009) 115010

[17] S. J. Moon, S. S. Lee, H. S. Lee, T. H. Kwon, Fabrication of microneedle array using LIGA and hot embossing process, Microsys. Tech. 11 (2005) 311-318

[18] C. Y. Jin, M. H. Han, S. S. Lee, Y. H. Choi, Mass producible and biocompatible microneedle patch and functional verification of its usefulness for transdermal drug delivery, Biomed. Microdevices 11 (2009) 1195-1203

[19] A. Trautmann, F. Heuck, C. Mueller, P. Ruther, $O$. Paul, Replication of microneedle arrays using vacuum casting and hot embossing, Transducers '05, Digest of Technical Papers 2 (2005) 1420-1423

[20] M. Han, D.-H. Hyun, H.-H. Park, S. S. Lee, C.-H. Kim, C. Kim, A novel fabrication process for out-ofplane microneedle sheets of biocompatible polymer, J. Micromech. Microeng. 17 (2007) 1184-1191
[21] M. A. Woodruff, D. W. Hutmacher, The return of a forgotten polymer-Polycaprolactone in the 21st century, Prog. Polymer Sci. 35 (2010) 1217-1256

[22] P. Griss, G. Stemme, Side-opened out-of-plane microneedles for microfluidic transdermal liquid transfer, J. MEMS 12 (2003) 296-301

[23] R.S. Petersen, S.S. Keller, A. Boisen, Loading of Drug-Polymer Matrices in Microreservoirs for Oral Drug Delivery, Macromol. Mat. Eng. 302 (2017) 1600366

[24] L.H. Nielsen, J. Nagstrup, S. Gordon, S.S. Keller, J. Østergaard, T. Rades, A. Müllertz, A. Boisen, $\mathrm{pH}$-triggered drug release from biodegradable microwells for oral drug delivery, Biomed. Microdevices, 17(3) (2015) 9958

[25] J. S. Kochhar, T. C. Quek, W. J. Soon, J. Choi, S. Zou, L. Kang, Effect of Microneedle Geometry and Supporting Substrate on Microneedle Array Penetration into Skin, J. Pharm. Sci. 102 (2013) 41004108 